\title{
Intestinal parasites in Polish community on the example of military environment
}

\author{
Krzysztof Korzeniewski ${ }^{1}$, Alina Augustynowicz ${ }^{1}$, Anna Lass $^{2}$ \\ ${ }^{1}$ Department of Epidemiology and Tropical Medicine in Gdynia, Military Institute of Medicine, Warsaw, Poland \\ ${ }^{2}$ Department of Tropical Parasitology in Gdynia, Medical University of Gdansk, Poland
}

\begin{abstract}
Background: The epidemiological situation concerning the prevalence of the majority of intestinal parasites in Poland has not been investigated in recent years and therefore is not known. Information on the prevalence of nematodes and most of cestodes is acquired from the studies carried out in Polish research centres. The aim of this study was to evaluate the occurrence of intestinal parasites among Polish soldiers who served in harsh environmental conditions in Afghanistan and their families living in Poland. The relation between the rates of infections in military personnel and in their families in the context of the risk of importing intestinal parasites from Afghanistan to Poland was also analysed in this article.

Materials and methods: 264 families consisting of 803 persons took part in the study which was conducted in the period May 2011 - December 2012. Stool samples were subjected to parasitological examination in the Military Institute of Medicine, Poland. The tests were performed by means of three diagnostic methods (direct smear, decantation, flotation). The study population comprised 264 married soldiers and 539 civilians (soldiers' wives and children) living permanently in urban areas in Poland.

Results: Intestinal parasites were diagnosed in 4/264 studied soldiers (1.5\% infected with Ascaris lumbricoides, Giardia intestinalis), in 9/253 studied women (3.6\% infected with A. lumbricoides, Hymenolepis nana, Taenia spp.) and in $5 / 286$ children (1.7\% infected with A. lumbricoides, G. intestinalis). There was no more than one infection per one household.

Conclusions: The occurrence of intestinal parasites among Polish soldiers shows the possibility of importing pathogens from the Third World countries. It also indicates, in the context of infected women and children, that the source of infection of parasites of the digestive tract can be present in Poland.
\end{abstract}

(Int Marit Health 2014; 65, 4: 216-222)

Key words: intestinal parasites, military environment, Poland

\section{INTRODUCTION}

Soldiers deployed to areas of armed conflicts have been the largest professional group in the Polish society functioning in different climatic and sanitary conditions [1]. Staying in areas characterised by harsh environment creates the risk for infections with contagious or parasitic pathogens and the risk for importing air-borne, food-and water-borne as well as vector-borne diseases into a home country [2-4]. Medical services supporting military operations carried out overseas need to pay particular attention to gastrointestinal parasitic diseases since they are widespread in operation areas, they can be easily transmitted through the oral-faecal route, and because such infections often take a chronic and asymptomatic form [5]. Examination of Polish military personnel deployed to Chad in the period 2008-2009 demonstrated a great number of gastrointestinal parasitic illnesses. As a result of the screening tests carried out among members of the Polish Military Contingent (PMC) in Africa, a health prevention program against parasitic diseases of the digestive tract among participants of overseas military operations was 
introduced in the Polish Armed Forces (PAF) [6]. The main objective of the program is to detect and eradicate intestinal parasites in the Polish military environment. Measurable effects of the program were observed after only 4 years following its introduction (over 15,000 Polish soldiers were screened for parasitic infections in the period 2010-2013, the infected individuals received appropriate medical treatment; an overall rate of infected soldiers decreased from $15.4 \%$ in 2010 to less than $3 \%$ in 2013) [7]. Medical services conduct continuous epidemiological research into the prevalence of gastrointestinal parasitic diseases in the population of Polish soldiers; military personnel are regularly subjected to parasitological testing both at home and abroad. Recently, a decision has been taken that screening tests for parasitic infections should also be carried out among soldiers' families, their wives and children who are permanently residing in Poland and who have not travelled abroad for the past 3 years.

The aim of this study was to examine the occurrence of intestinal parasites among Polish soldiers who served between 2011 and 2012 in Afghanistan and among their families living in Poland. The authors also examined the relation between parasitic infections in soldiers and in their wives and children in the context of the risk of importing intestinal parasites from Afghanistan to Poland.

\section{MATERIALS AND METHODS}

\section{ETHICAL CONSIDERATIONS}

The paper was approved by the Polish Ministry of Science and High Education (Subject No. 113/2011, Military Institute of Medicine in Warsaw, Poland).

\section{STUDY POPULATION}

264 families consisting of 803 persons took part in the study which was conducted in the period May 2011-December 2012. The examined population comprised 264 soldiers and 539 civilians (253 wives and 286 children). Included in the study were married soldiers who served in military unit No. 1641 in Poland, as well as in the PMC in Afghanistan between 2011 and 2012, and soldiers' families (wives, children) in Poland. All of the examined persons were living permanently in urban areas. The studied soldiers were assigned to the military unit in Inowroclaw, Poland. Between 2011 and 2012 they were participating for 6 months in a military operation carried out in Afghanistan. They were serving in harsh environmental conditions there. Polish soldiers were screened for parasitic diseases of the digestive tract 4-8 weeks before the end of their tour of duty in Afghanistan. The tests were part of the health prevention program against intestinal parasitic diseases among soldiers serving in overseas military operations, which has been carried out in the PAF [6]. Single parasite infections were detected in 3 out of 264 examined soldiers (Ascaris lumbricoides, Hymenolepis nana, Giardia intestinalis). All of the infected soldiers received adequate antiparasitic treatment in Afghanistan and 7 days after coming back to Poland they were screened for parasitic infections once more (a follow-up test upon completion of the antiparasitic therapy). The soldiers were tested while they were undergoing an army medical examination. The test results proved negative for all of the 264 examined soldiers, including the 3 infected individuals. 12-16 weeks following their return from Afghanistan, 264 soldiers were subjected to yet another parasitological diagnostics tests (performer as a part of the research study discussed in this article). The purpose of the examination was to detect parasitic infections which might have been acquired during the last few weeks spent in Afghanistan or the first few weeks in Poland. Wives and children (aged 1-15) living in the same households were examined for intestinal parasites at the same time as the soldiers. The reason for this was a potential risk of importing parasitic pathogens from Afghanistan by their husbands and fathers.

\section{FIELD PROCEDURES AND SAMPLE COLLECTION}

Three faecal samples were collected from each of the studied soldiers and their family members at intervals of 2-3 days. The biological material was collected in labelled stool containers, fixed in $10 \%$ formalin or sodium acetate-acetic acid-formalin preservative and then transported to the Department of Epidemiology and Tropical Medicine of the Military Institute of Medicine in Gdynia, Poland for parasitological examination. The examination was conducted by means of light microscopy using 3 different methods (direct smear, decantation, flotation). In total, diagnosticians tested 2,376 faecal specimens collected from the military personnel and 4,851 specimens collected from soldiers' wives and children ( 3 methods $\times 3$ samples from each of the studied person).

\section{LABORATORY PROCEDURES}

The diagnostics of intestinal parasites was performed by means of 3 stool testing methods using a light microscopy [8]:

Direct smear in Lugol's solution. Approximately $2 \mathrm{mg}$ of stool was collected with a glass rod and applied onto a slide, a drop of Lugol's solution was added and the material was smeared over a $4 \mathrm{~cm}^{2}$ surface. Next, a cover slide was placed on top of the preparation and the material was examined microscopically under $\times 20$ magnification objective.

Preparation from decantation in distilled water. Approximately $2 \mathrm{~mL}$ of stool specimen was mixed thoroughly with a small amount of water in a test tube. Next, water was 
Table 1. Distribution of age of the study participants $(n=803)$

\begin{tabular}{|c|c|c|c|c|c|}
\hline Study participants & Number & Mean age & Standard deviation & Median age & Age range \\
\hline Soldiers & 264 & 36.9 & 7.1 & 37 & $23-54$ \\
\hline Infected & 4 & 33.6 & 8.4 & 38 & $24-41$ \\
\hline Non-infected & 260 & 36.8 & 7.0 & 37 & $23-54$ \\
\hline Wives & 253 & 35.5 & 6.9 & 35 & $22-54$ \\
\hline Infected & 9 & 36.6 & 7.5 & 36 & $26-50$ \\
\hline Non-infected & 244 & 35.5 & 6.9 & 35 & $22-54$ \\
\hline Children & 286 & 7.9 & 3.9 & 8 & $1-15$ \\
\hline Infected & 5 & 5.6 & 3.6 & 4 & $2-10$ \\
\hline Non-infected & 283 & 7.9 & 3.9 & 8 & $1-15$ \\
\hline
\end{tabular}

Table 2. Results of stool examination in study participants $(n=803)$

\begin{tabular}{|c|c|c|c|c|c|c|c|c|c|}
\hline \multirow[t]{2}{*}{$\begin{array}{l}\text { Study } \\
\text { participants }\end{array}$} & \multirow[t]{2}{*}{ Number } & \multicolumn{2}{|c|}{$\begin{array}{l}\text { Ascaris } \\
\text { Iumbricoides }\end{array}$} & \multicolumn{2}{|c|}{$\begin{array}{l}\text { Hymenolepis } \\
\text { nana }\end{array}$} & \multicolumn{2}{|c|}{ Taenia spp. } & \multicolumn{2}{|c|}{$\begin{array}{l}\text { Giardia } \\
\text { intestinalis }\end{array}$} \\
\hline & & Positive & Per cent & Positive & Per cent & Positive & Per cent & Positive & Per cent \\
\hline Soldiers & 264 & 3 & 1.14 & 0 & 0 & 0 & 0 & 1 & 0.38 \\
\hline Wives & 253 & 6 & 2.37 & 2 & 0.8 & 1 & 0.4 & 0 & 0 \\
\hline Children & 286 & 4 & 1.4 & 0 & 0 & 0 & 0 & 1 & 0.35 \\
\hline Total & 803 & 13 & 1.62 & 2 & 0.25 & 1 & 0.12 & 2 & 0.25 \\
\hline
\end{tabular}

added to the top of the tube and mixed. After 30 min the supernatant was decanted and another portion of water was added. This procedure was repeated until clear supernatant was obtained, generally 3 to 4 times. The sediment was then placed on a slide and stained with Lugol's solution for microscopic examination (objective $\times 40$ magnification).

Preparation from Fülleborn's flotation. Approximately $2 \mathrm{~mL}$ of stool specimen was mixed with saturated $\mathrm{NaCl}$ solution in a test tube. $\mathrm{Next}, \mathrm{NaCl}$ solution was added to the top of the tube. A cover slide was placed gently on the top of the tube and in contact with the suspension. After 30 min the cover slide was gently removed with tweezers and placed the wet side down on a slide. The preparation was ready for microscopic examination (objective $\times 10$ magnification).

\section{STATISTICAL ANALYSIS}

Chi-squared tests for independence were used for qualitative variables (with the use of Yates correction for cell counts below 10, with check of Cochrane's conditions or with Fisher's exact test, respectively). In all the calculations the statistical significance level of $p=0.05$ has been used.

\section{RESULTS}

The tests for intestinal parasites which were conducted in the population of 264 soldiers, men whose mean age was 36.9 (Table 1), deployed to Afghanistan between 2011 and 2012 for 6 months, and serving in Poland throughout the study period (May 2011 - December 2012), revealed intestinal pathogens in 4 of the examined persons $(1.5 \%$ of the study population); they were 3 nematode (Ascaris lumbricoides) and 1 protozoan infection (Giardia intestinalis) (Table 2). The infected soldiers have not reported any gastrointestinal symptoms, which might have indicated an infection with intestinal parasites. None of the infected soldiers' family members, tested at the same time, was diagnosed with pathogenic intestinal parasites.

Intestinal pathogens were detected in 9 out of 253 examined soldiers' wives (3.6\% of the study population) whose mean age was 35.5 (Table 1). They included 6 nematode (Ascaris lumbricoides) and 3 cestode infections (2 Hymenolepis nana, 1 Taenia spp.) (Table 2). None of the infected women's husbands or children, examined at the same time, was diagnosed with pathogenic intestinal parasites. The infected women have not reported any gastrointestinal symptoms which might have indicated an infection with intestinal parasites.

Additionally, intestinal pathogens were detected in 5 out of 286 examined children, which accounted for $1.7 \%$ of the study population. The examined group comprised 131 boys and 155 girls whose mean age was 7.9 (Table 1 ). There were 4 cases of nematodes (Ascaris lumbricoides) and 1 case of protozoan infection (Giardia intestinalis) (Table 2). None of the infected children's fathers or mothers was diagnosed with pathogenic intestinal parasites. The infected children 
have not reported any gastrointestinal symptoms which might have indicated an infection with intestinal parasites.

As regards nematode infections, there was no statistically significant correlation between the rates of infections in soldiers and in their wives (the value of the statistic test $\chi^{2}=1.15, p=0.2831$ ) and in their children (the value of the test statistic $\chi^{2}=0.08, p=0.7840$ ). As regards cestode infections, there was no statistically significant correlation between the rates of infections in soldiers and in their wives (the value of the statistic test $\chi^{2}=3.15, p=0.0760$ ). As regards infections with pathogenic protozoa, there was no statistically significant correlation between the rates of infections in soldiers and in their children (the value of the statistic test $\chi^{2}=0.42, p=0.5164$ ).

\section{DISCUSSION}

Despite significant progress in laboratory diagnostics, parasitic diseases of the digestive tract are still among the greatest challenges of modern medicine. More than 2 billion people worldwide are estimated to be infected with intestinal parasites; approximately 5 billion people live in endemic areas $[9,10]$. There are a number of factors which facilitate the spread of infections in the Third World countries as well as increase the risk of importing parasitic infections into developed countries. These factors commonly include climate change, mass migration, poor sanitation, poverty, lack of medical care, immunodeficiency and the presence of hosts in some ecosystems (reservoirs of parasites) [11-16]. Similarly, the prevalence of intestinal parasitic diseases in humans is high in developing countries as well. This is mainly due to limited financial and organisational capabilities. Such limitations impede the process of infections control or the introduction of appropriate medical treatment and health prevention programs $[9,13]$. As regards European countries, high rates of parasitic infections refer to the countries in the third and fourth quartile according to gross domestic product per capita (GDP $\$ 1,809-\$ 17,630$ ). Poland is one of such countries [17]. The epidemiological situation as to the prevalence of the majority of intestinal parasitic diseases in Poland (nematodes and most of cestodes) has not been investigated in recent years and therefore is not known. The last major population study in Poland was conducted in the academic year 2002-2003. The examined group comprised 31,504 7-year-old children from 15 out of 16 Polish provinces. Intestinal parasites were detected in 4,584 children (14.55\% of the study population, including $10.4 \%$ children from urban areas and $19 \%$ children from rural environment). The most commonly detected parasites were Enterobius vermicularis (3,827 cases, $12.15 \%$ of all infected), Ascaris lumbricoides (263 cases, $0.83 \%$ ), and Giardia intestinalis (217 cases, $0.69 \%$ ). The authors compared the results of their examination with the ones acquired from previous studies carried out among 7-year-old school-children as part of a national campaign conducted every 5 years in the 1980s and 1990s. They concluded that the epidemiological situation as regards the prevalence of intestinal parasitoses in Polish children has been systematically improving [18].

The difficulties in acquiring comprehensive data on health condition of citizens inhabiting African or Asian countries (especially if they live in war-torn regions) can be easily explained. However, the fact that nowadays there is no data available on the prevalence of intestinal worm infections in Poland, one of the largest and most populous European countries, is simply astonishing. The current list of notifiable food- and/or water-borne parasitic diseases in Poland includes giardiasis, cryptosporidiosis, echinococcosis, cysticercosis and trichinellosis. Yet, there is no legal requirement to report other parasitic diseases and therefore e.g. the number of ascariasis infections (the most common helminthiasis in the world), enterobiasis and other intestinal nematode infections is unknown. This situation is due to the introduction of the Law on prevention and control of infections and infectious diseases in humans in 2008 [19], 19 items were excluded from the list of notifiable diseases, including all nematode and the majority of cestode infections. This has led to a situation in which the disease reports prepared in the Centre for Monitoring and Analysis of Epidemiological Situation at the Department of Epidemiology in the National Institute of Public Health - National Institute of Hygiene no longer include the majority of cases of intestinal parasitoses. The Department of Prevention and Control of Infections and Infectious Diseases in Humans at the Chief Sanitary Inspectorate is unable to assess the risk of developing of intestinal parasitic diseases (nematodes and most of cestodes) in the general Polish population, and sanitary-epidemiological stations are not required to monitor this type of infections. The reports on the occurrence of intestinal parasites in the Polish population had been written until December 2008, i.e. until the above-mentioned Act came into force. In 2008, the reported cases of parasitic infections included, among others, 5,817 cases of ascariasis, 5,666 cases of enterobiasis, 3,182 cases of giardiasis [20]. Since 2009, the data on the occurrence of intestinal parasites (except for the above-mentioned foodand/or water-borne parasitic diseases, such as giardiasis and cryptosporidiosis) in the Polish population has been based mainly on individual research programs and projects undertaken by research centres and health care facilities. Similarly, in other European countries the main focus of epidemiological surveillance of intestinal parasitoses is on monitoring protozoan infections, giardiasis and cryptosporidiosis. The number of giardiasis cases in Europe have been relatively constant over the past 5 years. In 2011 , a total of 16,475 confirmed cases were reported by 
23 European countries. The highest notification rate was observed in Bulgaria (26 per 100,000) followed by Estonia (18 per 100,000), Sweden (11 per 100,000) and Iceland (10 per 100,000). The overall crude rate for giardiasis in the European Union (EU) and European Economic Area (EEA; Iceland, Lichtenstein, Norway) countries was 5.49 cases per 100,000 population $(1,736$ cases were reported in Poland in 2011, 4.51 per 100,000; in 2012 - 1,653 cases, 4.29 per 100,000). The disease was most commonly diagnosed in children under the age of 5 , with the highest case rate for males (11.2 cases per 100,000). Cryptosporidiosis cases in Europe have also been relatively constant over the past 5 years. In 2011, 5,697 confirmed cases were reported by 21 EU/EEA countries. The highest rate was observed in Ireland (9 per 100,000) followed by United Kingdom (5 per $100,000)$. The overall crude rate in the EU/EEA countries was 1.95 per 100,000 population (only 1 case was reported in Poland in 2011, in 2012 - 2 cases). The highest rate of cryptosporidiosis in Europe was observed in 0-4-year-old male children (13.8 cases per 100,000 population) [21]. According to Bajer [22], the National Institute of Hygiene in Poland does not report human cases of cryptosporidiosis although they are officially registered; the annual number of human giardiasis in Polish population is probably also underestimated.

At present, population screening for all intestinal parasites in Poland is only carried out in the PAF. It is conducted in accordance with the requirements of the health prevention program. Soldiers engaged in overseas military operations have been routinely screened for nematode, cestode, trematode and protozoa infections since 2010 [6]. Between 2011 and 2012, 7,589 Polish soldiers serving in Afghanistan were tested for intestinal parasites. Stool specimens were collected and fixed in the area of operations and then transported to Poland where they were tested by means of 3 different methods using light microscopy. The diagnostic tests were performed and the antiparasitic treatment of the infected soldiers was administered 4-8 weeks before the end of the tour of duty in Afghanistan. The types of parasitic infections in soldiers serving in PMC in Afghanistan between 2011 and 2012 are presented in Table 3.

Seven days after coming back from the operation area abroad Polish soldiers are screened for parasitic infections once more. They are tested during an army medical examination aimed at assessing their general health status. Personnel serving in Afghanistan who develop an intestinal infection in the mission area need to undergo a follow-up parasitological examination after they receive abroad appropriate antiparasitic treatment (the follow-up tests are conducted in Poland during an army medical examination). Due to the fact that military personnel may acquire a parasitic infection during their last few weeks spent in Afghanistan
Table 3. Parasitic infections in soldiers serving in Polish Military Contingent in Afghanistan between 2011 and 2012

\begin{tabular}{|c|c|c|}
\hline Parasitic infections & Number* & Percentage ${ }^{\#}$ \\
\hline \multicolumn{3}{|l|}{ Single parasite infections } \\
\hline Ascaris lumbricoides & 121 & 1.59 \\
\hline Strongyloides stercoralis & 4 & 0.05 \\
\hline Trichuris trichiura & 1 & 0.01 \\
\hline Enterobius vermicularis & 1 & 0.01 \\
\hline Hymenolepis nana & 28 & 0.37 \\
\hline Hymenolepis diminuta & 1 & 0.01 \\
\hline Taenia spp. & 2 & 0.03 \\
\hline Dicrocoelium dendriticum & 3 & 0.04 \\
\hline Giardia intestinalis & 136 & 1.79 \\
\hline Cryptosporidium parvum & 9 & 0.12 \\
\hline Entamoeba histolytica/dispar & 10 & 0.13 \\
\hline Total & 316 & 4.16 \\
\hline \multicolumn{3}{|l|}{ Co-infections } \\
\hline$A l+G i$ & 5 & 0.07 \\
\hline$A l+H n$ & 2 & 0.03 \\
\hline$A l+S s$ & 1 & 0.01 \\
\hline$A l+E h / d$ & 1 & 0.01 \\
\hline$H n+G i$ & 1 & 0.01 \\
\hline Total & 10 & 0.13 \\
\hline
\end{tabular}

*Number of infected soldiers $(n=314)$; "Percentage of examined soldiers $(\mathrm{n}=7,589) ; \mathrm{Al}$-Ascaris lumbricoides; Ev - Enterobius vermicularis; Ss -

Strongyloides stercoralis; $\mathrm{Hn}$ - Hymenolepis nana; $\mathrm{Hd}$ - Hymenolepis diminuta; T - Taenia spp.; Dd - Dicrocoelium dendriticum; Gi - Giardia intestinalis; E h/d-Entamoeba histolytica/dispar

or the first few weeks in Poland, the authors of this article decided to conduct a research study focusing on a selected group of 264 soldiers serving in Afghanistan, permanently assigned to a military unit No. 1641 in Poland and on their families. These soldiers were among 7,589 members of the PMC deployed to Afghanistan in 2011-2012. Single parasitic infections were detected in 3 out of 264 examined soldiers (Ascaris lumbricoides, Hymenolepis nana, Giardia intestinalis). All of the infected soldiers received antiparasitic treatment in Afghanistan and had a follow-up parasitological test 7 days after coming back to Poland, all tests proved negative. Thus, 4 of the soldiers from the military unit No. 1641 who were diagnosed with parasitic infections 12-16 weeks after returning to Poland might have become infected either during the last few weeks in Afghanistan or during the first few weeks in Poland.

Poland is the only NATO member who has introduced obligatory parasitological tests for all its soldiers deployed to overseas military operations. In other armies, only those soldiers who report to a health care facility with pathological symptoms need to undergo parasitological diagnostics. 
Parasitological tests performed among the United States Forces soldiers in the period from 2002 to 2012 revealed 8,381 cases of intestinal parasitic diseases. These are, however, approximate estimates, as only a part of pathogens were laboratory-confirmed. Additionally, infection rates may be underestimated because not all soldiers suffering from gastrointestinal symptoms sought medical assistance but rather tried to cure themselves. The most common intestinal parasites among the United States Forces soldiers in the analysed period were nematodes $(n=3,818)$, cestodes $(n=$ $=2,358)$, trematodes $(n=346)$ and protozoa $(n=1,859)[23]$.

The data on parasitic infections in Poland, apart from the data collected in the military environment in recent years, is also available from publications of other researchers whose studies have demonstrated a significant proportion of intestinal parasitoses among treated patients. Parasitological tests are most commonly conducted among children who were hospitalised due to gastrointestinal symptoms and were then diagnosed for parasitic infections. Raś-Noryńska et al. [24] have screened 998 hospitalised children and adolescents aged 9 months - 17 years. Pathogenic intestinal parasites were detected in $6.8 \%$ of the study group, Giardia intestinalis was the dominant infection. Screening tests conducted by Wasilewska et al. [25] among 938 hospitalised children and adolescents aged 1-18 revealed Ascaris lumbricoides infections in as much as $26.9 \%$ of the study population. Żukiewicz et al. [26] performed screening tests for intestinal parasites among children and adolescents aged 5 months - 18 years treated both on an out-patient and in-patient basis. As much as $75 \%$ out of 120 studied patients were infected with pathogenic intestinal parasites, Ascaris lumbricoides was the dominant infection (more than $55 \%$ of the infected patients) [26]. Since most of intestinal parasitic diseases are not required by law to be reported to government authorities, the interest in conducting research into the prevalence of intestinal parasites has been steadily decreasing. Only a few research centres in Poland (mainly in Gdynia, Poznan, and Lublin) perform parasitological diagnostics, mostly for scientific purposes. They use different testing methods, in particular concentration techniques (flotation, sedimentation) in light microscopy. Regrettably, the majority of laboratories in Poland which apply microscopic diagnostics for the purposes of parasitological testing mainly use the very basic direct smear method. This technique reduces the probability of detecting pathogens, and thus may cause false negative test results. The limitations of parasitological diagnostics are also due to lack of experience of many diagnosticians whose task is to perform parasitological tests. This fact is hardly surprising, given that the Centre for Medical Postgraduate Education in Poland does not offer courses in parasitological diagnostics and the specialisation in medical laboratory parasitology has been suspended for many years now. Consequently, the number of parasitologists has been steadily decreasing, and the so-called alternative medicine centres have been trying to exploit the gap in parasitological diagnostics in the Polish market. Instead of applying standard diagnostic procedures based on macroscopic and microscopic examination of faecal samples, smear of duodenal fluid aspirate, immunodiagnostics in parasitology, molecular diagnostics or in vitro cultivation of parasites, alternative medicine centres resort to diagnostic methods which have very little in common with parasitology. One of such alternative methods used for detecting intestinal parasites is, for instance, electro-acupuncture according to Voll (a test for parasites which does not require collection of biological material for testing) or DIACOM test (a diagnostic scanner). This may sound unbelievable, yet, this is the reality as regards alternative parasitological diagnostics in the $21^{\text {st }}$ century Poland - a European country perceived as culturally and economically developed, where professionals are being gradually replaced by persons without any medical knowledge or experience.

\section{CONCLUSIONS}

The occurrence of intestinal parasites among Polish soldiers shows the possibility of importing pathogens from the Third World countries. It also indicates, in the context of infected women and children, that the source of infection of parasites of the digestive tract can be present in Poland.

\section{ACKNOWLEDGEMENTS}

The authors acknowledge the command of military unit No. 1641 in Poland and the command of Polish Military Contingent in Afghanistan for their acceptance and help with the interviews and collecting of faecal samples from soldiers on duty.

\section{REFERENCES}

1. Korzeniewski K, Bochniak A. Medical support of military operations in Iraq and Afghanistan. Int Marit Health 2011; 62: 71-76.

2. Aronson NE, Sanders JW, Moran KA. In Harm's way: infections in deployed American Military Forces. Clin Infect Dis 2006; 43: 1045-1051.

3. Buczyński A, Korzeniewski K, Bzdęga I, Jerominko A. Epidemiology of parasitic diseases in persons treated in the Hospital of the United Nations Interim Force in Lebanon from 1993 to 2000. [in Polish]. Przegl Epidemiol 2004; 58: 303-312.

4. Korzeniewski K, Nitsch-Osuch A, Konarski M, Guzek A, Prokop E, Zieniuk K. Prevalence of acute respiratory tract diseases among soldiers deployed for military operations in Iraq and Afghanistan. Adv Exp Med Biol 2013; 788: 117-124.

5. Frickmann H, Schwarz NG, Wiemer DF et al. Food and drinking water hygiene and intestinal protozoa in deployed German soldiers. Eur J Microbiol Immunol 2013; 3: 53-60.

6. Korzeniewski K. Examination regarding the prevalence of intestinal parasitic diseases in Polish soldiers contingents assigned to missions abroad. Int Marit Health 2011; 62: 31-36. 
7. Korzeniewski K. Evaluation of the execution of the program of prevention against parasitic diseases of the digestive tract among participants of overseas military operations. Unpublished data. Military Institute of Medicine, Warsaw, Poland, 2014.

8. World Health Organisation. Basic laboratory methods in medical parasitology. Geneva 1991.

9. Hotez PJ, Molyneux DH, Fenwick A et al. Control of neglected tropical diseases. N Engl J Med 2007; 357: 1018-1027.

10. Horton J. Human gastrointestinal helminth infections: are they now neglected diseases? Trends Parasitol 2003; 19: 527-531.

11. El-Sherbini GT, Abosdera MM. Risk factors associated with intestinal parasitic infections among children. J Egypt Soc Parasitol 2013; 43: 287-294.

12. Ziegelbauer K, Speich B, Mäusezahl, Bos R, Keiser J, Utzinger J. Effect of sanitation on soil-transmitted infection: systematic review and meta-analysis. PLoS Med 2012; 9: e1001162.

13. Bethony J, Brooker S, Albonico M, Geiger SM, Loukas A, Diemert D, Hotez PJ. Soil-transmitted helminth infections: ascariasis, and hookworm. Lancet 2006; 367: 1521-1532.

14. de Silva NR, Brooker S, Hotez PJ, Montresor A, Engels D, Savioli L. Soil-transmitted helminth infections: updating the global picture. Trends Parasitol 2003; 19: 547-551.

15. Pham-Duc P, Nguyen-Viet H, Hattendorf J, Zinsstag J, Phung-Dac C, Zurbrügg C, Odermatt P. Ascaris lumbricoides and Trichuris trichiura infections associated with wastewater and human excreta use in agriculture in Vietnam. Parasitol Int 2013; 62: 172-180.

16. Schär F, Inpankaew T, Traub RJ et al. The prevalence and diversity of intestinal parasitic infections in humans and domestic animals in a rural Cambodian village. Parasitol Int 2014; 63: 597-603.

17. Hotez PJ, Gurwith M. Europe's neglected infections of poverty. Int $J$ Infect Dis 2011; 15: e611-19.
18. Bitkowska E, Wnukowska N, Wojtyniak B, Dzbeński TH. The occurrence of intestinal parasites among children attending first classes of the elementary schools in Poland in the school year 2002/2003. [in Polish]. Przegl Epidemiol 2004; 58: 295-302.

19. Journal of Laws No. 234, item 1570. Act of 5 December 2008 on prevention and control of infections and infectious diseases in humans [in Polish].

20. National Institute of Public Health. National Institute of Hygiene. Infectious diseases and poisonings in Poland in 2008. [in Polish]. Department of Epidemiology, Warsaw, Poland 2009.

21. European Centre for Disease Prevention and Control. Annual epidemiological report. Reporting on 2011 surveillance data and 2012 epidemic intelligence data. Stockholm: ECDC 2013. Accessed: 01 May 2014. Available at: www.ecdc.europa.eu.

22. Bajer A. Cryptosporidium and Giardia spp. infections in humans, animals and the environment in Poland. Parasitol Res 2008; 104: 1-17.

23. Medical Surveillance Monthly Report. Gastrointestinal Infections, Active Component, U.S. Armed Forces, 2000-2012. MSMR 2013; 20: 7-11.

24. Raś-Noryńska M, Białkowska J, Sokół R, Piskorz-Ogórek K. Parasitological stool examination from children without the typical symptoms of parasitic disease. Przegl Epidemiol 2011; 65: 599-603.

25. Wasilewska J, Kaczmarski MG, Sawicka-Żukowska M, Tomaszewska B, Majewska A, Plewa K. Analysis of clinical symptoms and selected hematological indices in hospitalized children with Ascaris lumbricoides infection from the northeastern region of Poland. Wiad Parazytol 2011; 57: 43-51.

26. Żukiewicz M, Kaczmarski M, Topczewska M, Sidor K, Tomaszewska BM. Epidemiological and clinical picture of parasitic infections in the group of children and adolescents from north-east region of Poland. Wiad Parazytol 2011; 57: 179-187. 